\title{
Nations' income inequality predicts ambivalence in stereotype content: How societies mind the gap
}

Article in British Journal of Social Psychology • October 2012

DOI: $10.1111 /$ bjso.12005 · Source: PubMed

CITATIONS

32

37 authors, including:

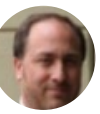

\section{Roberto González}

Pontifical Catholic University of Chile

70 PUBLICATIONS 918 CITATIONS

SEE PROFILE

Vanessa Smith-Castro

University of Costa Rica

42 PUBLICATIONS 515 CITATIONS

SEE PROFILE
READS

173

\section{Jacques-Philippe Leyens}

Université Catholique de Louvain

176 PUBLICATIONS $\quad 4,308$ CITATIONS

SEE PROFILE

\section{Miguel Moya}

University of Granada

139 PUBLICATIONS 2,311 CITATIONS

SEE PROFILE

Some of the authors of this publication are also working on these related projects:

Project

New Zealand Attitudes and Values Study View project

Desarrollo de herramientas psicológicas y computacionales de ayuda a la decisión para la prevención de la radicalización islamista de corte yihadista. View project 


\section{Nations' income inequality predicts ambivalence in stereotype content: How societies mind the gap}

Federica Durante ${ }^{1 *}$, Susan T. Fiske ${ }^{2}$, Nicolas Kervyn ${ }^{3}$, Amy J. C. Cuddy ${ }^{4}$, Adebowale (Debo) Akande ${ }^{5}$, Bolanle E. Adetoun ${ }^{6}$, Modupe F. Adewuyi ${ }^{7}$, Magdeline M. Tserere ${ }^{8}$, Ananthi Al Ramiah ${ }^{9}$, Khairul Anwar Mastor ${ }^{10}$, Fiona Kate Barlow ${ }^{11}$, Gregory Bonn ${ }^{12}$, Romin W. Tafarodi ${ }^{12}$, Janine Bosak ${ }^{13}$, Ed Cairns ${ }^{14}$, Claire Doherty ${ }^{14}$, Dora Capozza ${ }^{15}$, Anjana Chandran ${ }^{16}$, Xenia Chryssochoou ${ }^{17}$, Tilemachos latridis ${ }^{18}$, Juan Manuel Contreras ${ }^{2}$, Rui Costa-Lopes ${ }^{19}$, Roberto González ${ }^{20}$, Janet I. Lewis ${ }^{21}$, Gerald Tushabe ${ }^{22}$, Jacques-Philippe Leyens ${ }^{3}$, Renée Mayorga ${ }^{23}$, Nadim N. Rouhana ${ }^{24}$, Vanessa Smith Castro ${ }^{25}$, Rolando Perez ${ }^{25}$, Rosa Rodríguez-Bailón ${ }^{26}$, Miguel Moya ${ }^{26}$, Elena Morales Marente ${ }^{27}$, Marisol Palacios Gálvez ${ }^{27}$, Chris G. Sibley ${ }^{28}$, Frank Asbrock ${ }^{29}$ and Chiara C. Storari ${ }^{30}$ 'University of Milan - Bicocca, Italy

${ }^{2}$ Princeton University, New Jersey, USA

${ }^{3}$ Catholic University of Louvain at Louvain-la-Neuve, Belgium

${ }^{4}$ Harvard Business School, Boston, Massachusetts, USA

${ }^{5}$ Institute of Research on Global Issues, Tshwane, South Africa

${ }^{6}$ Economic Commission for West Africa (Ecowas), Abuja, Nigeria

${ }^{7}$ Emory University, Atlanta, Georgia, USA

${ }^{8}$ National Prosecuting Authority, Pretoria, South Africa

${ }^{9}$ University of Oxford, UK

${ }^{10}$ University Kebangsaan Malaysia, Bangi, Malaysia

I'University of Queensland, St Lucia, Australia

${ }^{12}$ University of Toronto, Ontario, Canada

*Correspondence should be addressed to Federica Durante, Dipartimento di Psicologia, Università di Milano-Bicocca, Piazza dell'Ateneo Nuovo I, 20126 Milano, Italy (e-mail: federica.durante@unimib.it).

After the first four authors, the remaining authors are listed alphabetically by the last name of our primary contact at the university. Nicolas Kervyn is now at Centre Emile Berheim, Solvay Brussels School of Economics and Management, ULB, Belgium; Ananthi Al Ramiah is now at Yale-NUS College, Singapore; Juan Manuel Contreras is now at Harvard University, USA; Gregory Bonn is now at Monash University Sunway Campus, Malaysia; Janine Bosak is now at Dublin City University Business School, Ireland. 
${ }^{13}$ University of Bern, Switzerland

${ }^{14}$ University of Ulster, UK

${ }^{15}$ University of Padova, Italy

${ }^{16}$ Bangalore, India

${ }^{17}$ Panteion University of Social and Political Sciences, Athens, Greece

${ }^{18}$ University of Crete, Greece

${ }^{19}$ ICS - University of Lisbon, Portugal

${ }^{20}$ Pontificia Universidad Católica de Chile, Santiago, Chile

${ }^{21}$ Harvard University, Cambridge, Massachusetts, USA

${ }^{22}$ Makerere University, Kampala, Uganda

${ }^{23}$ University of Lima, Peru

${ }^{24}$ Tufts University, Medford, Massachusetts, USA

${ }^{25}$ University of Costa Rica, San Pedro, Costa Rica

${ }^{26}$ University of Granada, Spain

${ }^{27}$ University of Huelva, Spain

${ }^{28}$ University of Auckland, New Zealand

${ }^{29}$ Philipps University Marburg, Germany

${ }^{30}$ University of Lausanne, Switzerland

Income inequality undermines societies: The more inequality, the more health problems, social tensions, and the lower social mobility, trust, life expectancy. Given people's tendency to legitimate existing social arrangements, the stereotype content model (SCM) argues that ambivalence-perceiving many groups as either warm or competent, but not both-may help maintain socio-economic disparities. The association between stereotype ambivalence and income inequality in 37 cross-national samples from Europe, the Americas, Oceania, Asia, and Africa investigates how groups' overall warmth-competence, status-competence, and competition-warmth correlations vary across societies, and whether these variations associate with income inequality (Gini index). More unequal societies report more ambivalent stereotypes, whereas more equal ones dislike competitive groups and do not necessarily respect them as competent. Unequal societies may need ambivalence for system stability: Income inequality compensates groups with partially positive social images.

Inequality corrodes human relations. As Alexis de Tocqueville (1835/2003) noted, material differences divide people socially, and obstruct empathy, favouring exploitation and slavery. Coming from aristocratic France, in 1831, de Tocqueville travelled the United States, impressed by the 'equality of conditions' (p. 11), which, in his opinion, helped Americans to trust each other. Indeed, for thousands of years the quality of human life has improved by raising material living standards, but nowadays for rich countries to get richer adds nothing to quality of life (Wilkinson \& Pickett, 2010). What instead seems to matter the most in developed nations is the level of inequality in society, namely, the size of income disparities.

Many problems plague more unequal societies: The more inequality, the more health problems, social tensions, and the lower life expectancy, social mobility, education, trust, happiness, and well-being (see Wilkinson \& Pickett, 2009, for a review). If on the one hand, both history and recent events (e.g., the Arab spring, the Occupy movement) argue in favour of people's need for justice and therefore for fighting against inequality, on the other hand, both history and recent events (e.g., the economic crisis) show the existence 
of a perplexing degree of acquiescence that contributes to the maintenance of unequal systems. Certainly, collective actions have played a critical role in reducing inequality. However, when considering the level of persistent disparity within and between societies, the relative lack of collective actions may seem surprising.

The American historian Howard Zinn (1968) claimed that 'society's tendency is to maintain what has been' and 'rebellion is only an occasional reaction' (p. 16; cited in Jost, Banaji, \& Nosek, 2004). Social psychologists Jost and Banaji (1994) offer an explanation for such a tendency by arguing that individuals are inclined to rationalize the status quo, thus perceiving the existing social arrangements that affect them as fair, legitimate, and justified. The stereotype content model (SCM; Fiske, Cuddy, Glick, \& Xu, 2002) suggests that depicting societal groups in ambivalent ways-such as fortunate in one sphere while unfortunate in another-may mask socio-economic disparities, facilitating, as a consequence, the rationalization and maintenance of the status quo. Using the SCM, the present work begins to investigate the relationship between ambivalent societal stereotypes and income inequality across nations, hypothesizing that the more unequal a society is the more ambivalence appears as a rational buffer that helps to conceal inequality and maintain the system.

\section{Ambivalence and the SCM}

Among the functions of stereotypes, Tajfel (1981) argued that stereotypes contribute to the maintenance of the system 'explaining or justifying a variety of social actions' (p. 146). More recently, ambivalent stereotypes especially appear to serve this function because they paint both advantaged and disadvantaged groups as possessing distinctive but counterbalanced strengths and weaknesses, as if every 'class gets its share' (Lane, 1959, p. 39), leading people to perceive society as fair (Glick \& Fiske, 2001; Kay \& Jost, 2003).

Underlying ambivalent stereotypes, favourable and unfavourable biases co-exist, beyond outgroup antipathy (e.g., Eagly \& Kite, 1987; Eagly \& Mladinic, 1989; Glick \& Fiske, 1996, 2001, 2011; Katz \& Hass, 1988). In this context, the SCM (Fiske et al., 2002) innovates by looking at various stereotypes simultaneously and from society's perspective, as shared, cultural, public images. Not only are many societal stereotypes ambivalent, combining both hostile and favourable beliefs about a group, but also warmth and competence (W-C) are the two basic dimensions capturing cultural contents. Although labels differ (socially vs. intellectually good-bad, Rosenberg, Nelson, \& Vivekananthan, 1968; communion vs. agency, Bakan, 1966; see also Abele \& Wojciszke, 2007), W-C repeatedly appear as basic dimensions of social judgment (see Cuddy, Fiske, \& Glick, 2008; Fiske, Cuddy, \& Glick, 2007) and intergroup behaviour (Cuddy, Fiske, \& Glick, 2007) because they help individuals' social interactions, indicating how helpful or harmful a target may be (Fiske et al., 2002).

Ambivalent combinations of competence and warmth also emerge in compensationhypothesis studies (Judd, James-Hawkins, Yzerbyt, \& Kashima, 2005), revealing trade-offs of competence and warmth when people rate individuals or groups in a comparative context. A compensatory process occurs when a positive perception on one dimension is offset by a negative perception on the other: Participants tried to 'rectify this disparity [on one dimension] by asserting that the situation must be reversed on the other dimension of social judgment' (Judd et al., 2005, p. 910), but only on competence and warmth (see Kervyn, Yzerbyt, \& Judd, 2010, for a review).

According to the SCM, competence and warmth judgments, respectively, stem from perceived socio-economic status (high-low) and perceived interdependence 
(cooperative-competitive). These socio-structural factors predict groups' location on the competence-warmth stereotype map (Fiske, 2012; Fiske et al., 2002, 2007). Crossing status and interdependence, four kinds of stereotype content emerge: High-status, cooperative groups seem both competent and warm, a univalent and positive stereotype; low-status, competitive groups receive univalent but negative stereotypes, seeming both cold and incompetent. High-status, competitive groups are ambivalently judged as competent, but not warm; whereas low-status, cooperative groups are ambivalently considered as warm, but incompetent.

Stereotype content model hypotheses - perceived competence and warmth differentiate groups' stereotypes, many ambivalent (or mixed), with status predicting competence, and competition predicting (low) warmth - have extensive support, using a wide range of target groups: Occupations, nationalities, ethnicities, socio-economic groups, religions, and gender subtypes (see Cuddy et al., 2008; for a review). Most relevant here, Cuddy et al. (2009) tested SCM hypotheses using eight European (mostly individualistic) and three East Asian (collectivistic) samples, finding cross-cultural similarities on the main SCM hypotheses, with cross-cultural differences (more modest, collectivistic cultures do not locate reference groups in the high-high cell). SCM provides a pancultural tool for predicting group stereotypes from structural relations with other groups in society, and for comparing across societies.

As noted, individuals are inclined to maintain the status quo rather than to subvert it and this might be particularly true for high-status people (e.g., Schmitt, Branscombe, \& Kappen, 2003). However, favourable attitudes towards the preservation of the social order, albeit unjust, are also shared, at least under certain conditions, by disadvantaged groups (Jost et al., 2004; Kay et al., 2009; Lane, 1959; Stott \& Drury, 2004; Tajfel, 1981). Holding ambivalent beliefs about social categories may help people (especially the more deprived) to tolerate their situation (e.g., Jackman, 1994) because when one's group is low on one dimension, it is rewarded on the other. For this reason, ambivalent stereotypes can legitimate the status quo in ways that purely hostile stereotypes cannot (Fiske et al., 2002). Because people are more likely to endorse collective actions only when injustice is relatively clear (see Ellemers \& Barreto, 2009), these subtle, ambivalent forms of prejudice may discourage people from challenging unequal systems. Becker and Wright (2011) have indeed recently shown that exposure to benevolent sexism (Glick \& Fiske, 1996, 2011), a paternalistic belief that portrays women as 'wonderful but incompetent', hence best suited for low-status positions, decreases women's engagement in collective action, while exposure to hostile sexism increases it (both effects were mediated by system justification motives).

Ambivalent gender stereotypes are in fact more prevalent in countries with higher gender inequality at a societal level (Brandt, 2011; Glick et al., 2000, 2004). Furthermore, social problems more reliably associate with income distribution 'when income differences are measured across nation-states and other large geo-political units' (Wilkinson \& Pickett, 2007, p. 1966). Hence, to explore the ambivalence-inequality association, our cross-national study used SCM theory and method to investigate the ambivalent warmth-competence relationship and its relationship with an incomeinequality measure, namely, the Gini index (Brandolini \& Smeeding, 2007).

\section{Hypotheses}

To establish comparability with earlier efforts, we first tested the four SCM hypotheses, namely, how social groups were rated in warmth, competence, status, and competition, 
expecting that: Societal groups would array on perceived W-C (Hypothesis 1); many groups would appear either more competent or more warm (but not necessarily both or neither; Hypothesis 2); perceived status would positively correlate with competence (Hypothesis 3), and competition negatively with warmth (Hypothesis 4).

The inequality hypotheses investigated first overall correlations between W-C, and whether these co-varied with Gini inequality coefficients. The Gini index measures the degree of inequality in the distribution of income within a society. As calculated by the American Central Intelligence Agency, the cumulative family income is plotted against the number of families arranged from the poorest to the richest. Low Gini coefficients indicate a more equal distribution, with 0 corresponding to complete equality, and 100 corresponding to complete inequality. ${ }^{1}$

We considered a society as more ambivalent when the overall W-C correlation, calculated across societal groups within each sample, was around zero: The less correlated the W-C dimensions, the more the society's groups appear as a cloud of points, rather than a vector, as they would under a high warmth-competence correlation. The more circular cloud reflects the distribution of many groups into the ambivalent quadrants of the space; the vector shape would show most groups being univalent, low-low or highhigh. Thus, we expected higher inequality (Gini) to be associated with lower W-C correlation coefficients (Hypothesis 5). This would fit greater inequality requiring more compensation.

The inequality focus also compared how stereotypic traits and their respective sociostructural predictors (status-competence, competition-warmth) vary across societies. Perhaps viewing some groups ambivalently helps mask the status-competence dimension as the main source of social difference, emphasizing the competition-(low)warmth dimension as an additional source of social difference. A group might appear low status and low competence, but compensated by stereotypically appearing cooperative and friendly. This mechanism, that inequality could be masked by emphasizing another dimension besides status-competence, suggests the hypothesis that correlations between inequality (Gini) and ambivalence (the warmth-competence correlation) will themselves be linked to variations in the competition-warmth correlation: In other words, the inequality-ambivalence association will depend on the way in which competitive groups are perceived in terms of warmth (Hypothesis 6).

Alternatively, correlations between inequality and ambivalence could result from compressing or exaggerating perceived status differences (vs. actual differences measured by the Gini). If societies tend to conceal inequality, then the competence attributed to high-status groups could be either minimized or alternatively inflated. Therefore, the inequality-ambivalence correlation would itself correlate with the status-competence correlation, showing either compression, as when people endorse egalitarian principles (negative correlation), or exaggeration, as when people endorse meritocracy (positive correlation; Hypothesis 7).

\section{Method}

Data were collected in: Australia, Belgium, Bolivia, Canada, Chile, Costa Rica, England, Greece, India, Israel, Italy, Malaysia, Mexico, Northern Ireland, New Zealand, Peru,

\footnotetext{
' Gini coefficients were retrieved from Central Intelligence Agency-The World Factbook, https://www.cia.gov/library/publications/ the-world-factbook/fields/2 I 72.html July, 201 I.
} 
Portugal, South Africa, Spain, Switzerland, and Uganda. Data from South Korea, Japan, Hong Kong, and United States (US) were retrieved from previous studies (Cuddy et al., 2009; Fiske et al., 2002, Study 1) and reanalysed here.

\section{Preliminary groups-listing study}

Following Fiske et al. (2002) and Cuddy et al. (2009), in each country a preliminary study identified societal groups considered most salient. In their respective native languages, approximately 1,379 participants, mostly students, 55.14\% female, sample sizes between 28 and 100, averaging 25.07 years, voluntarily completed a self-administered, open-ended questionnaire listing: What various types of people their society categorizes into groups; which groups were considered to be of very low status; and of which groups they consider themselves to be member.

These questions aimed to identify relevant social groups in the least constrained way, insuring that all types of groups would be mentioned. Groups listed by at least $15 \%$ of participants then appeared in that country's main survey questionnaire. Across samples, the number of distinct groups ranged between 14 (Chile) and 33 (Bolivia, UPB-CB; Table SI.1 in the online supporting information presents demographic information for each sample). Overall, 235 different societal groups were listed, many of which were context specific (i.e., 140 social categories were mentioned only in one preliminary study). Given present purposes, we checked for the possibility that specific target groups would be chosen only in more equal versus unequal countries. We considered the societal groups listed in at least 10 of $29^{2}$ preliminary studies (i.e., 19 societal groups: Blacks, Catholic people, children, Christians, disabled people, gays, immigrants, Jews, men, middle-class, Muslims, old people, poor people, rich people, students, unemployed people, women, working class, young people). For each target group, we took into consideration the Gini coefficients of the countries in which it was listed, and then calculated the median, thus obtaining 19 Gini medians. They ranged from 33.70 to 39.20 , just on either side of the overall median Gini (37.60) of the countries in which the 29 preliminary studies were carried out. Results showed that all these groups were mentioned about equally in both high versus low equal countries.

\section{Main survey}

\section{Samples and participants}

Thirty-seven samples were recruited, one from each of the countries mentioned, with the exceptions of: Australia (two samples, Asian- and European-Australians), Bolivia (four different Bolivian universities' campuses ${ }^{2}$ ), Israel (two samples, Israeli-Jews and -Arabs), Italy (two samples, students and non-students), New Zealand (two samples, Europeanand Maori-New Zealanders), Northern Ireland (two samples, Catholic and Protestant Irish), Switzerland (four samples, Swiss-German students, Swiss-Italian students, SwissFrench students, and Swiss-French non-students), United States (two samples, students and non-students).

\footnotetext{
${ }^{2}$ In Switzerland, three preliminary studies (one in each canton), and in Israel two preliminary studies (one for Israeli-Jews and one for Israeli-Arabs) were carried out. In Bolivia, data for the long survey were collected in four universities' campuses located in two Bolivian cities. In Cochabamba, both the preliminary groups-listing study and the long survey were conducted at the Universidad Privada Boliviana-Cochabamba (UPB-CB). In La Paz, the preliminary groups-listing study was at the Universidad Mayor de San Andres (UMSA), whereas the long survey was at the UMSA, Universidad Catolica Boliviana (UCB), and Universidad Privada Boliviana (UPB).
} 
Respondents $(N=3,229)$ voluntarily participated in the main survey. Sample sizes varied $(n=30-272)$, mostly students, $61.04 \%$ female, mean age 23.7 years (Table SI.2 in the online supporting information presents demographic information for each sample).

\section{Questionnaire and procedure}

In their native languages, participants rated the groups from their countries' respective preliminary studies on items reflecting warmth, competence, status, and competition. ${ }^{3}$ Two items measured each construct (Appendix SI.A online presents all items) on 5-point scales $(1=$ not at all to $5=$ extremely $)$. As in previous SCM studies, participants rated how the groups are viewed at a cultural level: 'We intend to investigate the way societal groups are viewed by the [...] society. Thus, we are not interested in your personal beliefs, but in how you think they are viewed by others'. This instruction aimed to reduce social desirability concerns and to detect socially shared group stereotypes, in effect collective lay theories about how groups interrelate.

\section{Results}

Reliabilities, for each construct, within each sample, were generally sufficient: Competence $\alpha=.64-.93$ (median $=0.85$ ); warmth $\alpha=.54-.93$ (median $=0.75$ ); status $\alpha=.60-.95($ median $=0.86) ;$ and competition $\alpha=.56-.95($ median $=0.71){ }^{4}$

\section{SCM hypotheses}

As in previous SCM studies, to test whether groups' stereotypes fell along the two primary dimensions, competence and warmth scores for each societal group were averaged across participants within each sample. These means indeed arrayed groups in a twodimensional Competence $\times$ Warmth space (Hypothesis 1). Two types of cluster analysis examined its structure: Hierarchical cluster analysis (Ward's, 1963, method, which minimizes within-cluster variance and maximizes between-cluster variance) helped determine the best-fitting number of clusters; then, $k$-means cluster analyses examined which groups fit into which cluster. For 25 of 37 samples (67\%), agglomeration statistics from the hierarchical cluster analysis pointed to a four-cluster solution. Five clusters were, instead, the best fit for the 12 remaining samples - Asian- and White-Australian, Canadian, English, Greek, Indian, European- and Maori-New Zealand, Malaysian, Japanese, Spanish, and Ugandan samples.

To test for ambivalent stereotypes (Hypothesis 2), in each sample, competence and warmth means were compared within (paired $t$-test) and between (independent $t$-test) clusters. To be identified as ambivalent (either high-competence/low-warmth [HC-LW] or low-competence/high-warmth [LC-HW]), a cluster had to meet two conditions established previously (Cuddy et al., 2009; Fiske et al., 2002): W-C means differed significantly; a cluster's mean for the high dimension was higher than a cluster low on that dimension, and its mean for the low dimension was lower than a cluster high on that dimension. As expected, the majority of groups ended up in ambivalent clusters in 20 of 37 samples.

\footnotetext{
${ }^{3}$ Status and competition ratings are not available for the Mexican sample.

${ }^{4}$ Reported alpha medians include the following unsatisfactory alphas: Warmth, Indian sample $(\alpha=.49)$; Status, Israeli-Arab sample $(\alpha=.44)$; Competition, Swiss-German sample $(\alpha=.30)$, and the four Bolivian samples (UPB $\alpha=.26$; UPB-CB $\alpha=.39 ;$ UMSA $\alpha=.43 ;$ UCB $\alpha=.48)$.
} 
Three exceptions (Portugal and Northern Ireland - Catholic sample) were all univalent or all ambivalent (Japan). Two samples showed an almost equivalent numbers of groups contained in univalent versus ambivalent clusters (Indian, 17 vs. 16 groups, and Swiss German, 13 vs. 14 groups, respectively), whereas the remaining 12 samples showed more groups gathered in univalent than ambivalent clusters (Appendix SI.B online presents cluster analysis results for each sample).

Although in each country participants evaluated their own societal groups, some groups present in most societies, such as immigrants (labelled also as illegal immigrants or migrant workers), and unemployed people consistently ended up in the low-competence/low-warmth (LC-LW) cluster across cultures. We could furthermore notice some regional idiosyncrasies: For instance, in the European samples, the group Gypsies is included in the LC-LW cluster, whereas in the South American samples we found the group illiterates in that quadrant. The high-competence/high-warmth cluster, instead, comprised the ingroups and the reference groups, which vary from society to society. The LC-HW cluster consistently included old people, children, and disabled people, as the HC-LW consistently included rich people.

To test SCM structure-trait predictions (Hypotheses 3 and 4), status and competition scores for each societal group were averaged across participants within each sample, and their means correlated with competence and warmth means, respectively. As expected, perceived status positively correlated with competence $(r s=.74-.99$, all $p \mathrm{~s}<.001$; average $r=.90$ ). Perceived competition-warmth correlations averaged $r=-.32$ : Ranging from $r=-.42$ to -.92 , $p$ s $<.05$, in 15 of 36 samples $^{3}$; three samples were marginal, ps < .07: $r=-.37,-.35$, and -.36 . Unexpectedly, perceived competition correlated positively with warmth in the Israeli-Arab sample $(r=.45, p<.05)$. The remaining competition-warmth correlations were non-significant, but 11 were in the predicted negative direction whereas 6 were not (see Table 1). As in previous data sets using these methods, the average status-competence correlation showed twice the effect size of the average (negative) competition-warmth correlation.

Overall, Hypotheses 1-4 were supported in all our samples. Because each society rated its own social categories, these results suggest that evaluating different target groups does not affect the SCM basic tenets.

\section{Ambivalence and inequality hypotheses}

The distribution of target groups, within each sample, in the Competence $\times$ Warmth space suggested degrees of ambivalence: Higher degrees in some samples (a circular cloud of points, showing a zero warmth-competence correlation; e.g., Figure 1), lower degrees in others (a vector, from bottom left to top right, showing a positive warmth-competence correlation; e.g., Figure 2). Thus, W-C relate to each other in different ways, in different societies. As said, to measure different patterns across nations, we considered the overall W-C correlation within each sample as an index of ambivalence: The lower the W-C correlation, the greater the ambivalence; the higher a positive $\mathrm{W}-\mathrm{C}$ correlation, the lower the ambivalence.

Warmth and competence correlations were calculated at the target-group level within each sample. As Table 1 illustrates, correlations ranged between -.19 (ns) and .91 $(p<.001)$, average $r=.40$. Of 37 samples, 16 showed a small, non-significant W-C correlation, that is, a higher degree of ambivalence according to our definition. Because the number of groups evaluated by participants in each sample varied (i.e., from 14 to 33), we also considered $R^{2}$ as an estimate of W-C correlations' effect size. The $R^{2}$ of the 
Table I. Stereotypic traits correlations, social-structure stereotype correlations, Gini coefficients, all samples

\begin{tabular}{|c|c|c|c|c|c|c|}
\hline Sample & $\begin{array}{c}\text { Warmth- } \\
\text { competence } \\
r\end{array}$ & $\begin{array}{c}\text { Status- } \\
\text { competence } \\
r\end{array}$ & $\begin{array}{c}\text { Competition- } \\
\text { warmth } \\
r\end{array}$ & $\begin{array}{c}\text { Competition- } \\
\text { competence } \\
r\end{array}$ & $\begin{array}{c}\text { Status- } \\
\text { warmth } \\
r\end{array}$ & Gini \\
\hline Mexico & -.19 & Unavailable & Unavailable & Unavailable & Unavailable & 48.2 \\
\hline US (non-student) & -.09 & $.97^{* * * *}$ & $-.53 * *$ & $.55^{* *}$ & -.10 & 45.0 \\
\hline South Korea & -.07 & $.91 * * *$ & $-.42 *$ & $.83 * * *$ & -.30 & 31.4 \\
\hline Canada & -.03 & $.91 * * *$ & $-.56 * *$ & .19 & -.18 & 32.1 \\
\hline US (student) & -.03 & $.98 * * *$ & $-.67^{* * * *}$ & .33 & .01 & 45.0 \\
\hline Peru & -.01 & $.97 * * *$ & -.10 & $.97 * * *$ & .10 & 49.6 \\
\hline Japan & .03 & $.88 * * *$ & -.39 & .06 & .03 & 37.6 \\
\hline Israel (Jews) & .08 & $.99 * * *$ & $-.59 * *$ & $.48 *$ & .07 & 39.2 \\
\hline South Africa & .11 & $.78 * * * *$ & -.18 & .19 & -.25 & 65.0 \\
\hline Hong Kong & .12 & $.99 * * *$ & $-.37^{\dagger}$ & .26 & .12 & 53.3 \\
\hline Italy (student) & .23 & $.79 * * *$ & $-.70 * * *$ & .15 & -.14 & 32.0 \\
\hline Chile & .24 & $.97 * * *$ & -.14 & $.75^{\text {** }}$ & .11 & 52.4 \\
\hline Bolivia (UMSA) & .26 & $.90 * * *$ & .03 & $.76 * * *$ & .02 & 58.2 \\
\hline $\begin{array}{r}\text { Switzerland } \\
\text { (German) }\end{array}$ & .28 & $.93 * * *$ & $-.67 * * *$ & -.10 & .03 & 33.7 \\
\hline Italy (non-student) & .31 & $.75 * * *$ & $-.68 * * *$ & .14 & -.10 & 32.0 \\
\hline Costa Rica & .36 & $.89 * * *$ & $-.36^{\dagger \dagger}$ & $.66 * * *$ & .05 & 48.0 \\
\hline Bolivia (UCB) & $.39 *$ & $.94 * * *$ & -.17 & $.48^{* * *}$ & .25 & 58.2 \\
\hline Bolivia (UPB) & $.41^{*}$ & $.94 * * *$ & -.11 & $.49 * *$ & .36 & 58.2 \\
\hline England & $.46^{*}$ & $.93 * * *$ & $-.53 * *$ & $-.35^{\dagger}$ & $.48^{* *}$ & 34.0 \\
\hline Belgium & $.48^{*}$ & $.95 * * *$ & $-.92 * * *$ & $-.45^{\dagger}$ & $.65^{* *}$ & 28.0 \\
\hline New Zealand (Maori) & $.48^{* *}$ & $.96 * * *$ & -.02 & $.40 *$ & $.42^{*}$ & 36.2 \\
\hline $\begin{array}{l}\text { New Zealand } \\
\text { (European) }\end{array}$ & $.5 I^{* *}$ & $.91 * * *$ & -.30 & .27 & .34 & 36.2 \\
\hline Bolivia (UPB-CB) & $.54^{* *}$ & $.91 * * *$ & .25 & $.64^{* * *}$ & $.42^{*}$ & 58.2 \\
\hline Australia (European) & $.56 * *$ & $.94 * * *$ & $-.73 * * *$ & -.34 & $.45^{*}$ & 30.5 \\
\hline Uganda & $.57^{* *}$ & $.92 * * *$ & $.4 \mathrm{I}$ & $.89 * * *$ & .40 & 45.7 \\
\hline Spain & $.60^{* *}$ & $.92 * * *$ & $-.35^{\dagger \dagger}$ & .09 & $.53^{* *}$ & 32.0 \\
\hline Greece & $.61^{* *}$ & $.8 I^{* * * *}$ & -.14 & $.5 I^{* *}$ & .37 & 33.0 \\
\hline Portugal & $.61^{* *}$ & $.74 * * *$ & $-.67^{* *}$ & -.21 & .31 & 38.5 \\
\hline Australia (Asian) & $.65 * * *$ & $.95 * * *$ & .01 & $.45 *$ & $.63 * * *$ & 30.5 \\
\hline $\begin{array}{l}\text { Switzerland (French } \\
\text { student) }\end{array}$ & $.65^{* *}$ & $.87^{* * *}$ & $-.80 * * *$ & $-.48^{*}$ & .34 & 33.7 \\
\hline India & $.72 * * *$ & $.87^{* * * *}$ & .01 & $.5 I^{* *}$ & $.53 * * *$ & 36.8 \\
\hline Malaysia & $.74 * * *$ & $.93 * * *$ & .04 & $.49 * *$ & $.69 * * *$ & 44.1 \\
\hline Switzerland (Italian) & $.76 * * *$ & $.76 * * *$ & -.18 & .00 & $.39 *$ & 33.7 \\
\hline $\begin{array}{l}\text { Northern Ireland } \\
\text { (Catholic) }\end{array}$ & $.77^{* * * *}$ & $.95 * * *$ & $-.69 * * *$ & -.33 & $.70 * * *$ & 34.0 \\
\hline $\begin{array}{l}\text { Switzerland (French } \\
\text { non-student) }\end{array}$ & $.80 * * *$ & $.84 * * *$ & $-.66 * * *$ & $-.40^{\dagger}$ & $.46^{*}$ & 33.7 \\
\hline Israel (Arabs) & $.81^{* * * *}$ & $.80 * * *$ & $.45^{*}$ & $.66 * * *$ & $.60^{* *}$ & 39.2 \\
\hline $\begin{array}{l}\text { Northern Ireland } \\
\text { (Protestant) }\end{array}$ & $.91 * * *$ & $.92 * * *$ & -.25 & -.07 & $.78^{* * * *}$ & 34.0 \\
\hline
\end{tabular}

Note. Data are reported according to the warmth and competence correlations: Ascending order. ${ }^{*} p \leq .05 ; * * \leq .01 ; * * p \leq .001 ;{ }^{*} p$ between .052 and $.058 ;{ }^{\dagger \dagger} p=.07$. 


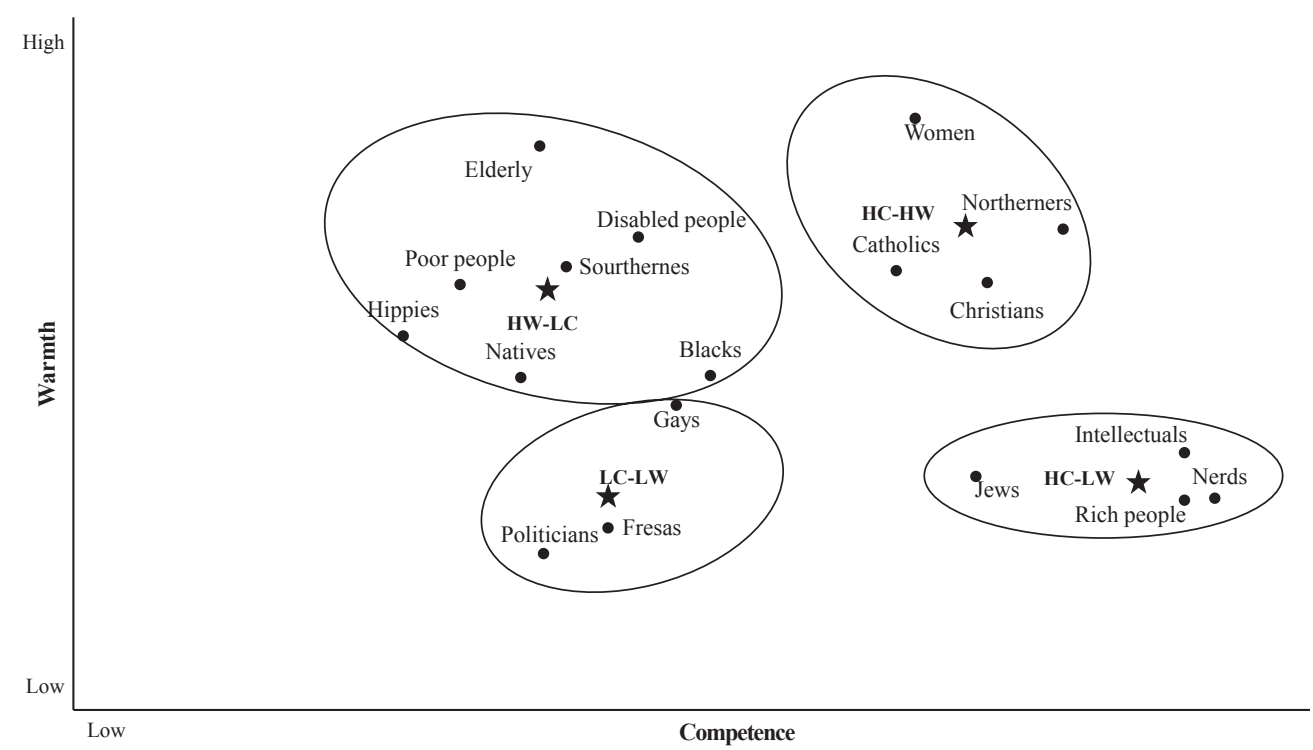

Figure I. Mexican sample, four-cluster solution. Stars indicate cluster centres. $H$ and $L$, respectively, indicate high and low; W, warmth; C, competence. The term 'fresas' refers to rich, spoiled kids.

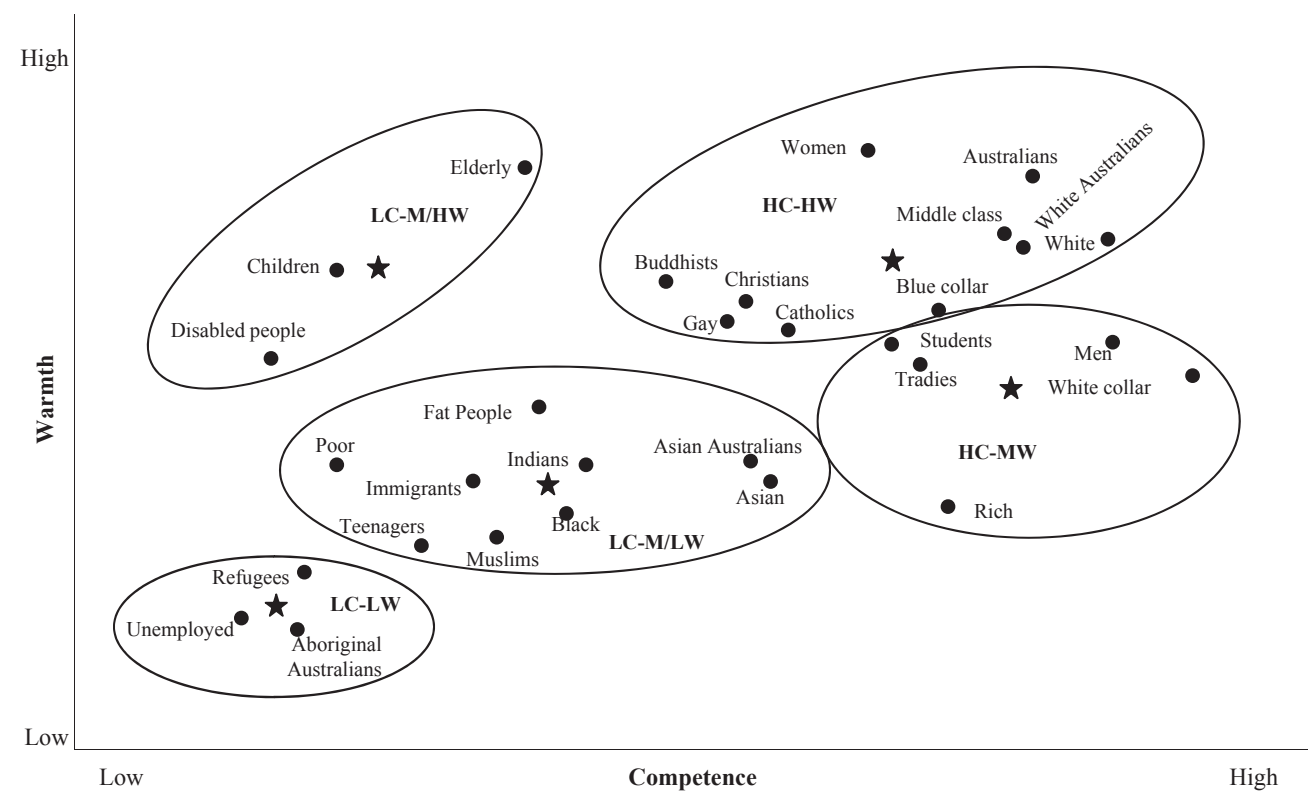

Figure 2. European Australian sample, five-cluster solution. Stars indicate cluster centres. $H, M$, and L, respectively, indicate high, medium, and low; $\mathrm{W}$, warmth; C, competence.

aforementioned 16 coefficients were also small, ranging from .0002 to .1283 . The remaining $21 \mathrm{~W}-\mathrm{C}$ correlation coefficients were positive and significant, ranging from $r=.39$ to .91 (all $p \mathrm{~s}<.05 ; R^{2}$ from .15 to .83 ), that is, a lower degree of ambivalence. As expected, the percentage of target groups gathered in ambivalent clusters was 
significantly higher in samples with small, non-significant W-C correlations (on average, $60.82 \%$ ) than in samples with positive, significant ones (on average, $44.72 \%$ ), $t(35)=2.03, p=.05$. Further correlations compared the percentages of HC-LW and LC-HW groups in each sample with the W-C correlations. The W-C coefficients significantly correlated with percentages of LC-HW groups, $r=-.48, p<.01$, but did not with percentages of HC-LW groups, $r=.09, p=.58$, suggesting that our ambivalence index was mostly driven by the LC-HW combinations.

Next, Fisher's z-transformation normalized the distribution of W-C coefficients, allowing us to correlate the standardized coefficients with the Gini ones. A significant correlation, $r=-.34, p<.05$, indicated that more ambivalent societies are also generally more unequal, supporting Hypothesis 5 (see Figure 3). Inequality emphasizes more than one dimension of intergroup perception (not just unequal status-competence but also differentiated competition-warmth) to compensate. ${ }^{5}$

The robustness of the inequality-ambivalence association was tested in several ways. First, in a regression analysis, Gini coefficients (centred around the mean), the number of groups rated by each sample (centred around the mean), and their interaction were regressed onto W-C correlations (Fisher standardized) to rule out the possibility that the number of target groups evaluated in each sample had an impact on the W-C correlation's size and, therefore, on the inequality-ambivalence association. The model explained $15.2 \%$ of variance. Gini was the best and only predictor $(\beta=-.33, p=.05)$; neither the number of groups $(\beta=.09, p=.60)$ nor the interaction term $(\beta=.16, p=.36)$ was significant.

Second, we further tested Hypothesis 5 by controlling for other potential related factors. Wilkinson and Pickett (2009) suggest that when inequality is measured across whole societies versus small areas, its association with social problems is 'stronger with inequality than with average income, and, in most cases, controlling for average income strengthens the associations with inequality' (p. 498). Therefore, in a regression analysis, both our measure of income inequality (Gini) and a measure of average income (GDP per capita 2009) ${ }^{6}$ were regressed onto the Fisher standardized W-C correlations. Results showed that Gini predicted W-C correlations $(\beta=-.39, p=.08)$ whereas GDP did not $\left(\beta=-.09, p=.69 ; R^{2}=11.6 \%\right)$.

Furthermore, arguably, the ideology concerning power and inequality in a given society (and not income inequality per se) might be responsible for the prevalence of ambivalent stereotypes. To control for the role of ideology, the Distance Power Index (PDI; Hofstede, 1980) ${ }^{7}$ was considered. PDI indexes the extent to which the less powerful members of a society accept and expect power to be distributed unequally, in other words, indexes the extent to which society's inequality is endorsed by those at the bottom of the social ladder as much as by those at the top. 'The fundamental issue here is how a society handles inequalities among people' (http://geert-hofstede.com/dimensions.

\footnotetext{
${ }^{5}$ A relevant issue not addressed in the present work concerns the country's ethnic mix of each sample, which might be reflected in the selected target groups. In fact, a society's remarkable ethnic divisions might account for the relationship between income inequality and social problems. However, although Wilkinson and Pickett (2009) argue that ethnicity is an important social marker for status differentiation, and, as such, it might worsen the social and health problems deriving from status, their review of more than I 50 studies suggests a primacy of income inequality over ethnicity (see also Wilkinson \& Pickett, 20 I0). Therefore, the ethnic composition of the societies investigated here are unlikely to account for the relationship between inequality and ambivalence.

${ }^{6}$ GDP per capita 2009 was retrieved from The World Bank, http://data.worldbank.org/country, August 201 I.

${ }^{7}$ PDI was retrieved from Geert Hofstede, http://geert-hofstede.com/countries.html, December 20 II (PDI is not available for Bolivia and Uganda, i.e., five samples).
} 


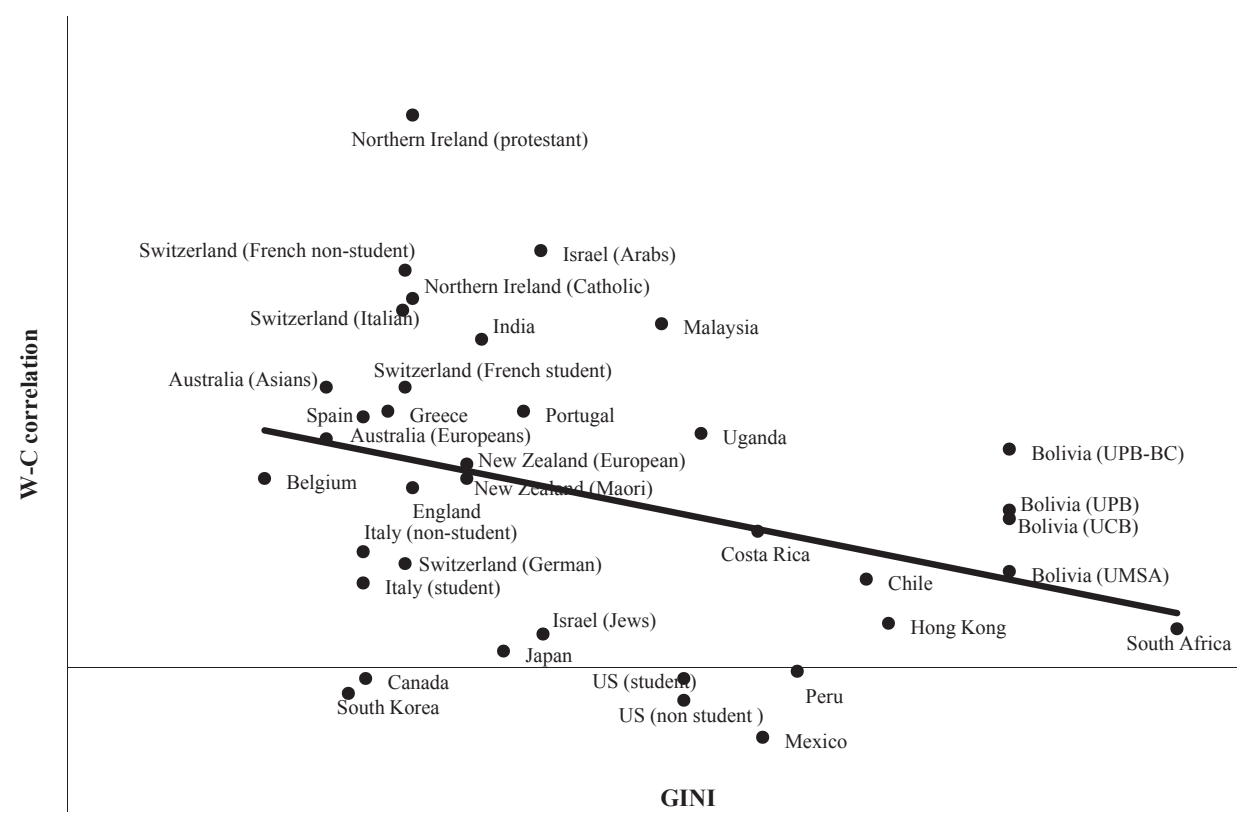

Figure 3. Gini coefficients and warmth-competence (W-C) Fisher standardized correlations, all samples.

html). Gini and PDI coefficients were regressed onto the Fisher standardized W-C correlations, and results showed that Gini predicted W-C correlations $(\beta=-.39, p<.05)$ whereas PDI did not $\left(\beta=-.06, p=.74 ; R^{2}=16.9 \%\right){ }^{8}$

Status-competence and competition-warmth correlations were also Fisher standardized and correlated with Gini coefficients. Testing Hypothesis 6 , competition-warmth and Gini coefficients significantly correlated, $r=.48, p<.01$, indicating that more equal societies show stronger negative competition-warmth associations; in other words, more equality, more dislike for competitive groups. In unequal societies, competition is more acceptable. Testing Hypothesis 7, no significant pattern was found for the Gini and the status-competence correlations $(r=.21, p=.23)$.

Finally, we checked for the unpredicted structure-trait combinations: Status-warmth and competition-competence correlations. As previously, they were calculated at the level of target groups within each sample; both unpredicted patterns were inconclusive: For competition-competence, average $r=.26,16$ positive correlations (range .40-.97, all $p s<.05)$, four negative correlations $(r=-.48, p<.05$; three marginally significant, $r=-.45,-.40,-.35$, all $p s<.06)$, the remaining 16 were non-significant. The statuswarmth average $r=.27,14$ positive correlations (range .39-.78, all $p$ s $<.05$ ), the remaining non-significant (see Table 1). Fisher standardized correlations with Gini coefficients showed that Gini coefficients significantly correlated with the competitioncompetence correlations $(r=.49, p<.01)$, indicating that in more equal societies being competitive does not necessarily imply being competent. Gini and status-warmth coefficients were only marginally associated $(r=-.29, p=.09)$, suggesting a tendency, in more egalitarian settings, to perceive high-status groups as warm.

\footnotetext{
${ }^{8} A$ regression analysis including Gini coefficients, and both GDP and PDI was also performed. Gini predicted W-C correlations $(\beta=-.42, \mathrm{P}=.053)$ whereas $\operatorname{GDP}(\beta=-.06, \mathrm{P}=.80)$ and $\mathrm{PDI}(\beta=-.08, \mathrm{P}=.69) \operatorname{did}$ not $\left(\mathrm{R}^{2}=17.1 \%\right)$.
} 
All the SCM correlations illustrated above and the Gini coefficients were finally correlated across samples. As Table 2 shows, when ambivalence is higher (i.e., low W-C correlations), both structural factors (i.e., status and competition) are more strongly related to competence. For lower degrees of ambivalence instead (i.e., high W-C correlation), status is associated with warmth. This latter result is not surprising given the very high status-competence correlation that we consistently find, which implies that any dimension correlating with competence (warmth in this case) will also correlate with status. Considering the Gini index, the cross-sample correlations therefore suggest that less egalitarian societies show more ambivalent stereotypes, and both high status and competition lead to perceiving groups as competent. More egalitarian societies, instead, have fewer ambivalent stereotypes, status and competition do not necessarily imply competence, and high-status groups tend to be perceived as warm.

Finally, given the cross-cultural nature of our data, the fact that scales' reliabilities, and sample sizes varied noticeably across countries, the SCM correlations and the moderating role played by income inequality were checked using meta-analytic techniques, which allow weighting correlations to minimize the variance between samples, and to correct for the unreliability of measures. Hedges and colleagues' method (Hedges \& Olkin, 1985; Hedges \& Vevea, 1998) was applied, and random-effects models were performed. ${ }^{9}$ On each SCM index, two meta-analyses were carried out: First, as suggested by Hedges and Vevea (1998), on Fisher standardized correlations; second, as recommended by Hunter and Schmidt (2004), on correlations corrected for unreliability (see Lipsey \& Wilson, 2001 for the formulas used). Inverse-variance-weighted mean effect sizes concerning the SCM correlations are summarized in Table 3. The significance of the average effect sizes can be inferred from the boundaries of the 95\% confidence intervals constructed around the mean effect size, which in all cases presented in Table 3 do not contain zero.

Next, inverse-variance-weighted regressions (random-effects model) assessed the relationship between SCM correlations and income inequality. Weighted regressions were performed on both Fisher standardized and corrected for unreliability correlations. Results, summarized in Table 4, corroborated our findings and provided some support for our Hypothesis 7. In fact, when the status-competence correlations were corrected for unreliability, the Gini index resulted a significant moderator of such a relationship, namely, more inequality more competence for high-status groups. In contrast, the unpredicted, marginally significant relationship between income inequality and statuswarmth associations disappeared when correlations were corrected for unreliability. Finally, note that inverse-variance-weighted regressions including Gini coefficients and other potential moderators (i.e., GDP and PDI) showed again the moderating role of income inequality on our W-C correlation (Fisher correlations: $\beta=-.41, p<.05$;

\footnotetext{
${ }^{9}$ All meta-analytic calculations reported in the present study were performed using the SPSS macro developed by Wilson (2005). Random-effects models were chosen because they account for both within-study variability and variability arising from differences between studies, in this case samples (see Hedges \& Vevea, 1998; Hunter \& Schmidt, 2000). In the Hedges and Vevea's (I998) method, random-effects models weight each study (i.e., sample) by the inverse of the sampling variance plus a constant that represents the variability across the population effects (Lipsey \& Wilson, 200I). According to several authors, real-world data are likely to have heterogeneous population effect sizes (e.g., Field, 200I, 2003; Hunter \& Schmidt, 2000, 2004), and randomeffects models should be the default approach in social sciences (Field \& Gillett, 2010). Furthermore, random-effects models 'allow inferences that generalize beyond the studies included in the meta-analysis (unconditional inferences)' (Field \& Gillett, 2010, p. 673; see also Hedges \& Vevea, 1998). Finally, the homogeneity test (Q statistic) of effect sizes was taken into consideration: When significant, it indicates that the variability across effect sizes exceeds what would be expected based on sampling error.
} 
Table 2. Across samples correlations among stereotype content model (SCM) indices and Gini coefficients

\begin{tabular}{lcccccc}
\hline SCM indices & 1 & 2 & 3 & 4 & 5 & 6 \\
\hline I. Warmth-competence & - & & & & \\
2. Status-competence & $-.38^{*}$ & - & & & \\
3. Competition-warmth & .19 & -.07 & - & & \\
4. Competition-competence & $-.34^{*}$ & .22 & $.68^{* * *}$ & - & \\
5. Status-warmth & $.87^{* * *}$ & -.01 & .15 & $-.29^{\dagger}$ & - \\
6. Gini & $-.34^{*}$ & .21 & $.48^{* *}$ & $.49^{* *}$ & $-.29^{\dagger}$ & - \\
\hline
\end{tabular}

Note. The SCM correlations used to compute this table were Fisher standardized.

${ }^{*} p \leq .05 ; * p \leq .01 ; * * * p \leq .001 ;{ }^{\dagger} p=.09$.

Table 3. Meta-analysis results. Random-effects models

\begin{tabular}{lcccccccr}
\hline $\begin{array}{l}\text { Stereotype content } \\
\text { model correlations }\end{array}$ & $N$ & $K$ & $r_{1}$ & $95 \% \mathrm{Cl}\left(r_{1}\right)$ & $I^{2}\left(r_{1}\right)$ & $r_{2}$ & $95 \% \mathrm{Cl}\left(r_{2}\right)$ & $I^{2}\left(r_{2}\right)$ \\
\hline Warmth-competence & 3,229 & 37 & .44 & $.33, .55$ & $93 \%$ & .51 & $.38, .65$ & $88.6 \%$ \\
Status-competence & 3,139 & 36 & .92 & $.90, .94$ & $93.2 \%$ & 1.09 & $1.04,1.13$ & $0.6 \%$ \\
Competition-warmth & 3,139 & 36 & -.38 & $-.49,-.25$ & $93.6 \%$ & -.44 & $-.58,-.30$ & $87.3 \%$ \\
Status-warmth & 3,139 & 36 & .29 & $.17, .40$ & $91.4 \%$ & .34 & $.20, .48$ & $88.9 \%$ \\
Competition-competence & 3,139 & 36 & .34 & $.18, .48$ & $95.5 \%$ & .38 & $.21, .55$ & $92.3 \%$ \\
\hline
\end{tabular}

Note. $N=$ total sample size for the given meta-analysis; $K=$ number of samples included in the metaanalysis; $r_{1}=$ inverse-variance-weighted mean effect size calculated on Fisher standardized correlations; $95 \% \mathrm{Cl}=95 \%$ confidence interval for the inverse-variance-weighted mean effect size $\left(r_{1}\right.$ and related $95 \%$ $\mathrm{Cl}$ reported in the table were converted back to $r$ ); $r_{2}=$ inverse-variance-weighted mean effect size on correlations corrected for unreliability; $I^{2}=$ index of heterogeneity (Higgins \& Thompson, 2002): It is based on the $Q$ homogeneity statistic (goodness of fit), $I^{2}=(Q-(K-I)) / Q$, multiplied by 100 to express it as percentage. Larger values of $I^{2}$, the more heterogeneity.

Table 4. Inverse-variance-weighted regression results (random-effects model). Moderating role of Gini coefficients on stereotype content model (SCM) correlations

\begin{tabular}{|c|c|c|c|c|c|c|}
\hline \multirow[b]{2}{*}{ SCM correlations } & \multicolumn{3}{|c|}{ Fisher standardized $r$} & \multicolumn{3}{|c|}{$r$ Corrected for unreliability } \\
\hline & $b(95 \% \mathrm{Cl})$ & $\beta$ & $p$ & $b(95 \% \mathrm{Cl})$ & $\beta$ & $p$ \\
\hline Warmth-competence & $-.0 \mathrm{I}(-0.03,-0.00 \mathrm{I})$ & -.33 & $<.04$ & $-.01(-0.02,0.002)$ & -.27 & .09 \\
\hline Status-competence & $.009(-0.005,0.022)$ & .20 & .22 & $.005(0.0003,0.009)$ & .36 & $<.05$ \\
\hline Competition-warmth & $.02(0.009,0.03)$ & .49 & $<.001$ & $.02(0.007,0.04)$ & .42 & $<.01$ \\
\hline Status-warmth & $-.01(-0.02,0.00 \mathrm{I})$ & -.28 & .08 & $-0 \mathrm{I}(-0.02,0.003)$ & -.26 & .12 \\
\hline Competition-competence & $.03(0.0 \mathrm{I}, 0.04)$ & .48 & $<.001$ & $.03(0.02,0.05)$ & .59 & $<.001$ \\
\hline
\end{tabular}

unreliability correction: $\beta=-.46, p<.05$ ), whereas results for GDP (Fisher correlations: $\beta=-.06, p=.79$; unreliability correction: $\beta=-.14, p=.53$ ) and PDI (Fisher correlations: $\beta=-.07, p=.69$; unreliability correction: $\beta=-.07, p=.71$ ) were nonsignificant. 


\section{Discussion}

Data from 37 cross-national samples showed the expected significant, negative association between SCM warmth-competence correlations and Gini coefficients, indicating that income inequality implicates ambivalence. Furthermore, SCM's hypothesized negative relationship between competition and warmth emerged as even stronger in more equal than unequal societies, showing more dislike for competitive groups when income differences are smaller. Finally, more equal societies do not necessarily perceive competitive groups as competent.

The SCM hypothesizes that many societal stereotypes are ambivalent. The present work supported this assumption, but also that different societies display different degrees of ambivalence, and that these relate to the societies' income differences. Warmth and competence here behaved consistently with the compensation effect (Judd et al., 2005), namely, groups perceived as low on one dimension are raised on the other. That such compensation appeared stronger in more unequal societies suggests that the more income inequality, the more social groups need to be rewarded, as if actual economic disparities are rationalized in social judgments.

Stereotype content model also hypothesizes that status predicts competence, whereas competition predicts (low) warmth. Status did predict competence in all samples, but this structure-trait combination did not correlate with societal income inequality, suggesting that both more and less equal societies share the meritocratic belief that status links to talent and abilities. Alternatively, as shown in Table 4, this result might be due to an error of measurement. In fact, when the status-competence correlations were corrected for unreliability, the Gini index became a significant moderator, showing that the more income inequality the more high-status groups are perceived as competent. Therefore, although this issue needs to be further investigated, it seems that more unequal societies tend to endorse meritocracy more than relatively equal ones, concealing inequality through exaggerating perceived status differences. Relatedly, status-warmth correlations were only marginally associated with income inequality, suggesting that in relatively equal countries, high-status groups also tend to be perceived as warm. However, when correlations were corrected for measures' unreliability, this tendency disappeared.

What instead consistently varies according to the degree of income inequality is the SCM-predicted competition-warmth association. More egalitarian societies especially perceive competitive groups as lacking warmth, suggesting that, given their relative income equality, competition seems unnecessary, so competitive groups are considered untrustworthy and perhaps exploitative. On the other hand, when economic disparities are bigger, people accept competition as inevitable: If competition is part of the system as a legitimate way to improve one's own position, then competitive groups are not disliked as much as in more egalitarian settings. These different views of competition held by relatively equal versus unequal societies also appear in the significant correlation between Gini coefficients and competition-competence correlations: The more inequality, the more people equate competition as competent (realistic behaviour), whereas the more equality, the less people think competition is necessarily competent.

Before discussing the theoretical and pragmatic implications of our findings, note that the majority of our samples came from relatively equal countries (23 samples: Gini between 28 and 39; 14 samples: Gini between 44 and 65). Adding data coming from more unequal countries as well as from countries with very high level of equality (e.g., Sweden, Norway) would allow us to optimally test our hypotheses. Furthermore, our participants 
were mostly students: Although convenience samples might seem risky, compared with representative samples, as they would tend to limit our results only to college student perceptions, this method is justified on three counts. First, the convenience samples, being similar, would tend to decrease the predicted cultural differences, providing a conservative test of our hypotheses. Second, demographic differences within country do not modify the results (Cuddy et al., 2007). Third, the SCM method asks for society's views, so it tends to emphasize a culturally shared lay theory of groups in society. Indeed, as suggested elsewhere, people from the same culture, whether actively biased or not, know their own cultural stereotypes (Devine, 1989; Fiske, 1993).

Nevertheless, especially in more unequal countries, access to higher education is linked to socio-economic status; consequently, it could be argued that our evidence may reflect the higher status people's point of view. Although, as noted above, SCM theory and method have proven a pancultural tool for detecting societal beliefs, future studies should extend these findings using more representative samples, and taking into account the role of the respondents' socio-economic position in addressing the ambivalence-inequality hypothesis: This would control for the possibility that higher versus lower status groups within a society would be more likely to hold ambivalent societal stereotypes in more unequal versus equal contexts, helping, furthermore, to theoretically bridge an individual level to a societal level analysis. However, United States, Italy, and Switzerland (French canton) results for student and non-student samples were very similar, as were results for non-student Maori (low-status group in New Zealand) and European New Zealanders (see Table 1).

The findings shed new light on how stereotypes potentially exert control. Stereotypes tell both how a given group of people allegedly do think, feel, behave (descriptively), and how they supposedly should think, feel, behave (prescriptively; Fiske, 1993). The descriptive and prescriptive aspects of stereotypes both exert social control, the description because it anchors social interactions to what is commonly believed about a certain group, the prescription because it demands the stereotyped group to conform to stereotypical expectations. In other words, 'stereotypes reinforce one group's or individual's power over another by limiting the options of the stereotyped group, so in this way stereotypes maintain power' and control (Fiske, 1993, p. 623). Furthermore, ambivalent stereotypes are also more easily accepted by the targets because the negative side of such beliefs is masked by the positive one (e.g., Eastwick et al., 2006). Thus, descriptive and prescriptive aspects of ambivalent stereotypes may even be appealing (hence more constraining) for stereotyped people who perceive their group to be socially appreciated in one way or another (i.e., warmth or competence). All this likely encourages people's acquiescence, while discouraging, even under great social and economic inequalities, social change and collective action.

This does not imply that people will never challenge unequal systems. What the present work depicts is a static picture taken at a particular historical time. The literature on active minorities, for instance, has documented the influence that, over time, minority groups can exert on majorities, leading to system change; socio-psychological reseach has devoted considerable attention to the conditions that facilitate collective action and social change (see van Zomeren \& Klandermans, 2011 [special issue]). Most relevant here, SCM links to the legitimacy and stability of status relations between groups as theorized by Tajfel (1981). In a recent work by Oldmeadow and Fiske (in press), groups were more differentiated on warmth in illegitimate than legitimate systems, but on competence in stable than unstable systems, highlighting the importance of the structural reality in shaping groups' stereotypes. Therefore, 
ambivalent stereotypes may be the cognitive alternative available in unjust (illegitimate) but stable systems. Future studies should investigate to what extent income inequality affects people's beliefs and behaviours when systems are perceived as legitimate/stable versus illegitimate/unstable.

However, because 'the content of stereotypes can serve to maintain ideological support for the prevailing social system' (Kay et al., 2007, p. 312), and specific ambivalent stereotypes link to system justification (Becker \& Wright, 2011; Jost \& Kay, 2005), ambivalence may be a system-justifying strategy endorsed at a macro-social level. Nowadays, given the evolution of democratic systems around the world, many societies (especially the most developed) need a way to maintain social control, supporting equality while facing severe economic disparities among people. Ambivalent societal stereotypes offer one solution. This seems indirectly supported by recent evidence showing that in the United States, 'stereotypes of 10 ethnic and national groups over 75 years revealed that as anti-prejudice norms grew stronger, historically negative aspects of stereotypes faded from mention' (Bergsieker, Leslie, Constantine, \& Fiske, 2012, p. 1232), but the negative content is implied (Kervyn, Bergsieker, \& Fiske, 2012), so 'modern stereotype assessment methods replicated the contemporary pattern of oftenambivalent stereotype content' (Bergsieker et al., 2012, p. 1232). All these findings highlight the insidious effects of ambivalent societal beliefs. The solution, however, cannot be to go back to hostile and overt forms of stereotypes and prejudice. Therefore, future studies should investigate how to contrast the deterrent effects of ambivalence on social change, especially in light of Wilkinson and Pickett's (2010) argument: 'The historical evidence confirms the primacy of political will. Rather than greater equality waiting till well-meaning governments think they can afford to make societies more equal, governments have usually not pursued more egalitarian policies until they thought their survival depend on it' (p. 241).

Arguably, over the past few decades, social psychology has progressively lost its connection to sociology, neglecting the influence of structural factors on people's behaviours (Oishi, Kesebir, \& Snyder, 2009): Modern social psychologists apparently lack a 'sociological imagination' (Mills, 1959) or 'the ability to look beyond personal experience and immediate situations to see the influence of social forces operating in a larger societal (or distal, macro) context' (Oishi et al., 2009, p. 336). The importance of considering distant factors was well documented, for example, in Durkheim's (1897/ 1951) classic analysis of how collective factors, such as the degree of social integration and moral regulation in a society, affected suicide rates across societies; in McClelland's (1961) pioneering work connecting changes in need for achievement within a society to changes in its economic activities; and in Nisbett and Cohen's (1996) work linking economic and historical factors to violent behaviours in the Southern United States (i.e., the culture of honour). Recently, Fiske (2011) argues for status as dividing people through upward envy and downward scorn; Oishi, Kesebir, and Diener (2011) have shown how income inequality (i.e., Gini) affected Americans' happiness over the past 37 years; and Loughnan et al. (2011) have demonstrated that greater self-enhancement is found in societies with higher Gini. All this points out that the nature of people's behaviour can be traced not only in individuals but also in the collective reality created by groups, societies, institutions; that is, macro factors can explain micro-psychological phenomena (Oishi et al., 2009; see also Oishi \& Graham, 2010). The current work likewise links distal factors (income inequality) and social beliefs (ambivalent societal stereotypes) across nations. Here, some sociological imagination appears. 


\section{Acknowledgements}

We thank Amir Goren and Riccardo Pedersini for comments on the manuscript. We deeply regret the death of our co-author, Professor Ed Cairns, on the 16th of February 2012 and extend our condolences to his family and friends.

\section{References}

Abele, A. E., \& Wojciszke, B. (2007). Agency and communion from the perspective of self versus others. Journal of Personality and Social Psychology, 93, 751-763. doi:10.1037/00223514.93.5.751

Bakan, D. (1966). The duality of human existence: An essay on psychology and religion. Chicago, IL: Rand McNally.

Becker, J. C., \& Wright, S. C. (2011). Yet another dark side of chivalry: Benevolent sexism undermines and hostile sexism motivates collective action for social change. Journal of Personality and Social Psychology, 101, 62-77. doi:10.1037/a0022615

Bergsieker, H. B., Leslie, L. M., Constantine, V. S., \& Fiske, S. T. (2012). Stereotyping by omission: Eliminate the negative, accentuate the positive. Journal of Personality and Social Psychology, 102, 1214-1238. doi:10.1037/a0027717

Brandolini, A., \& Smeeding, T. M. (2007). Inequality patterns in Western-type democracies: Crosscountry differences and time changes. Centre for Housebold, Income, Labour and Demographic economics - Italy. Retrieved from http://www.child-centre.unito.it/papers/ child08_2007.pdf

Brandt, M. J. (2011). Sexism and gender inequality across 57 societies. Psychological Science, 22, 1413-1418. doi:10.1177/0956797611420445

Cuddy, A. J. C., Fiske, S. T., \& Glick, P. (2007). The BIAS map: Behaviors from intergroup affect and stereotypes. Journal of Personality and Social Psychology, 92, 631-648. doi:10.1037/00223514.92.4.631

Cuddy, A. J. C., Fiske, S. T., \& Glick, P. (2008). Warmth and competence as universal dimensions of social perception: The Stereotype Content Model and the BIAS Map. In M. P. Zanna (Ed.), Advances in Experimental Social Psychology (Vol. 40, pp. 61-149). New York, NJ: Academic Press. doi:10.1016/S0065-2601(07)00002-0

Cuddy, A. J. C., Fiske, S. T., Kwan, V. S. Y., Glick, P., Demoulin, S., Leyens, J.-P., \& Ziegler, R. (2009). Is the stereotype content model culture-bound? A cross-cultural comparison reveals systematic similarities and differences. British Journal of Social Psychology, 48, 1-33. doi:10.1348/ $014466608 \times 314935$

de Tocqueville, A. (2003). Democracyin America. London: Penguin. (Originalwork published in 1835).

Devine, P. G. (1989). Stereotypes and prejudice: Their automatic and controlled components. Journal of Personality and Social Psychology, 56, 5-18. doi:10.1037/0022-3514.56.1.5

Durkheim, E. (1951). Suicide: A study in sociology (J. A. Spaulding \& G. Simpson, Trans.). New York, NY: Free Press. (Original work published 1897).

Eagly, A. H., \& Kite, M. E. (1987). Are stereotypes of nationalities applied to both women and men? Journal of Personality and Social Psychology, 53, 451-462. doi:10.1037/0022-3514.53.3.451

Eagly, A. H., \& Mladinic, A. (1989). Gender stereotypes and attitudes toward women and men. Personality and Social Psychology Bulletin, 15, 543-558. doi:10.1177/0146167289154008

Eastwick, P. W., Eagly, A. H., Glick, P., Johannesen-Schmidt, M., Fiske, S. T., Blum, A., ... Volpato, C. (2006). Is traditional gender ideology associated with sex-typed mate preferences? A test in nine nations. Sex Roles, 54, 603-614. doi:10.1007/s11199-006-9027-x

Ellemers, N., \& Barreto, M. (2009). Collective action in modern times: How modern expressions of prejudice prevent collective action. Journal of Social Issues, 65, 749-768. doi:10.1111/j.15404560.2009.01621.x 
Field, A. P. (2001). Meta-analysis of correlation coefficients: A Monte Carlo comparison of fixed and random-effects methods. Psychological Methods, 6, 161-180. doi:10.1037//1082-989X.6.2.161

Field, A. P. (2003). The problems in using fixed-effects models of meta-analysis on real-world data. Understanding Statistics, 2, 77-96. doi:10.1207/S15328031US0202_02

Field, A. P., \& Gillett, R. (2010). How to do a meta-analysis. British Journal of Mathematical and Statistical Psychology, 63, 665-694. doi:10.1348/000711010X502733

Fiske, S. T. (1993). Controlling other people. The impact of power on stereotyping. American Psychologist, 48, 621-628. doi:10.1037/0003-066X.48.6.621

Fiske, S. T. (2011). Envy up, scorn down: How status divides us. New York, NY: Russell Sage.

Fiske, S. T. (2012). Journey to the edges: Social structures and neural maps of inter-group processes. British Journal of Social Psychology, 51, 1-12. doi:10.1111/j.2044-8309.2011.02092.x

Fiske, S. T., Cuddy, A. J. C., \& Glick, P. (2007). Universal dimensions of social perception: Warmth and competence. Trends in Cognitive Sciences, 11, 77-83. doi:10.1016/j.tics.2006.11.005

Fiske, S. T., Cuddy, A. J. C., Glick, P., \& Xu, J. (2002). A model of (often mixed) stereotype content: Competence and warmth respectively follow from the perceived status and competition. Journal of Personality and Social Psychology, 82, 878-902. doi:10.1037// 0022-3514.82.6.878

Glick, P., \& Fiske, S. T. (1996). The Ambivalent Sexism Inventory: Differentiating hostile and benevolent sexism. Journal of Personality and Social Psychology, 70, 491-512. doi:10.1037/ 0022-3514.70.3.491

Glick, P., \& Fiske, S. T. (2001). An ambivalent alliance: Hostile and benevolent sexism as complementary justifications of gender inequality. American Psychologist, 56, 109-118. doi:10.1037/0003-066X.56.2.109

Glick, P., \& Fiske, S. T. (2011). Ambivalent sexism revisited. Psychology of Women Quarterly, 35, 530-535. doi:10.1177/0361684311414832

Glick, P., Fiske, S. T., Mladinic, A., Saiz, J. L., Abrams, D., Masser, B., ... López López, W. (2000). Beyond prejudice as simple antipathy: Hostile and benevolent sexism across cultures. Journal of Personality and Social Psychology, 79, 763-775. doi:10.1037/0022-3514.79.5.763

Glick, P., Lameiras, M., Fiske, S. T., Eckes, T., Masser, B., Volpato, C., ... Wells, R. (2004). Bad but bold: Ambivalent attitudes toward men predict gender inequality in 16 nations. Journal of Personality and Social Psychology, 86, 713-728. doi:10.1037/0022-3514.86.5.713

Hedges, L. V., \& Olkin, I. (1985). Statistical methods for meta-analysis. Orlando, FL: Academic Press.

Hedges, L. V., \& Vevea, J. L. (1998). Fixed- and random-effects models in meta-analysis. Psychological Methods, 3, 486-504. doi:10.1037/1082-989X.3.4.486

Higgins, J. P. T., \& Thompson, S. G. (2002). Quantifying heterogeneity in a meta-analysis. Statistics in Medicine, 21, 1539-1558. doi:10.1002/sim.1186

Hofstede, G. (1980). Culture's Consequences: International Differences in Work-related Values. Beverly Hills, CA: Sage.

Hunter, J. E., \& Schmidt, F. L. (2000). Fixed effects vs. random effects meta-analysis models: Implications for cumulative research knowledge. International Journal of Selection and Assessment, 8, 275-292. doi:10.1111/1468-2389.00156

Hunter, J. E., \& Schmidt, F. L. (2004). Methods of meta-analysis: Correcting error and bias in research findings. (2nd ed.) Newbury Park, CA: Sage.

Jackman, M. R. (1994). The velvet glove: Paternalism and conflict in gender, class, and race relations. Berkeley, CA: University of California Press.

Jost, J. T., \& Banaji, M. R. (1994). The role of stereotyping in system justification and the production of false consciousness. British Journal of Social Psychology, 33, 1-27. doi:10.1111/j.20448309.1994.tb01008.x

Jost, J. T., Banaji, M. R., \& Nosek, B. A. (2004). A decade of system justification theory: Accumulated evidence of conscious and unconscious bolstering of the status quo. Political Psychology, 25, 881-919. doi:10.1111/j.1467-9221.2004.00402.x 
Jost, J. T., \& Kay, A. C. (2005). Exposure to benevolent sexism and complementary gender stereotypes: Consequences for specific and diffuse forms of system justification. Journal of Personality and Social Psychology, 88, 498-509. doi:10.1037/0022-3514.88.3.498

Judd, C. M., James-Hawkins, L. J., Yzerbyt, V., \& Kashima, Y. (2005). Fundamental dimensions of social judgment: Understanding the relations between judgments of competence and warmth. Journal of Personality and Social Psychology, 89, 899-913. doi:10.1037/00223514.89.6.899

Katz, I., \& Hass, R. G. (1988). Racial ambivalence and American value conflict: Correlational and priming studies of dual cognitive structures. Journal of Personality and Social Psychology, 55 , 893-905. doi:10.1037/0022-3514.55.6.893

Kay, A. C., Gaucher, D., Peach, J. M., Friesen, J., Laurin, K., Zanna, M. P., \& Spencer, S. J. (2009). Inequality, discrimination, and the power of the status quo: Direct evidence for a motivation to view what is as what should be. Journal of Personality and Social Psychology, 97, 421-434. doi:10.1037/a0015997

Kay, A. C., \& Jost, J. T. (2003). Complementary justice: Effects of "poor but happy" and "poor but honest" stereotype exemplars on system justification and implicit activation of the justice motive. Journal of Personality and Social Psychology, 85, 823-837. doi:10.1037/00223514.85.5.823

Kay, A. C., Jost, J. T., Mandisodza, A. N., Sherman, S. J., Petrocelli, J. V., \& Johnson, A. L. (2007). Panglossian ideology in the service of system justification: How complementary stereotypes help us to rationalize inequality. Advances in Experimental Social Psychology, 39, 305-358. doi:10.1016/S0065-2601(06)39006-5

Kervyn, N., Bergsieker, H. B., \& Fiske, S. T. (2012). The innuendo effect: Hearing the positive but inferring the negative. Journal of Experimental Social Psychology, 48, 77-85. doi:10.1016/j. jesp. 2011.08.001

Kervyn, N., Yzerbyt, V. Y., \& Judd, C. M. (2010). Compensation between warmth and competence: Antecedents and consequences of a negative relation between the two fundamental dimensions of social perception. European Review of Social Psychology, 21, 155-187. doi:10.1080/ 13546805.2010.517997

Lane, R. E. (1959). The fear of equality. American Political Science Review, 53, 35-51. doi:10.2307/ 1951729

Lipsey, M. W., \& Wilson, D. B. (2001). Practical meta-analysis. Thousand Oaks, CA: Sage Publications.

Loughnan, S., Kuppens, P., Allik, J., Balazs, K., de Lemus, S., Dumont, K., \& Haslam, N. (2011). Economic inequality is linked to biased self-perception. Psychological Science, 22, 1254-1258. doi:10.1177/0956797611417003

McClelland, D. C. (1961). The achieving society. New York, NY: D. Van Nostrand.

Mills, C. W. (1959). Sociological imagination. New York, NY: Oxford University Press.

Nisbett, R. E., \& Cohen, D. (1996). Culture of honor: The psychology of violence in the South. Boulder, CO: Westview.

Oishi, S., \& Graham, J. (2010). Social ecology: Lost and found in psychological science. Perspectives on Psychological Science, 5, 356-377. doi:10.1177/1745691610374588

Oishi, S., Kesebir, S., \& Diener, E. (2011). Income inequality and happiness. Psychological Science, 22, 1095-1100. doi:10.1177/0956797611417262

Oishi, S., Kesebir, S., \& Snyder, B. H. (2009). Sociology: A lost connection in social psychology. Personality and Social Psychology Review, 13, 334-353. doi:10.1177/1088868309347835

Oldmeadow, J. A., \& Fiske, S. T. (in press). Contentment to resentment: Variation in stereotype content across status systems. Analysis of Social Issues and Public Policy. doi:10.1111/j.15302415.2011.01277.x

Rosenberg, S., Nelson, C., \& Vivekananthan, P. (1968). A multidimensional approach to the structure of personality impressions. Journal of Personality and Social Psychology, 9, 283-294. doi: $10.1037 / \mathrm{h} 0026086$ 
Schmitt, M. T., Branscombe, N. R., \& Kappen, D. M. (2003). Attitudes toward group-based inequality: Social dominance or social identity? British Journal of Social Psychology, 42, 161-186. doi:10.1348/014466603322127166

Stott, C., \& Drury, J. (2004). The importance of social structure and social interaction in stereotype consensus and content: Is the whole greater than the sum of its parts? European Journal of Social Psychology, 34, 11-23. doi:10.1002/ejsp.183

Tajfel, H. (1981). Human groups and social categories. Cambridge: Cambridge University Press.

Wilkinson, R. G., \& Pickett, K. E. (2007). The problems of relative deprivation: Why some societies do better than others. Social Science \& Medicine, 65, 1965-1978. doi:10.1016/j.socscimed. 2007.05 .041

Wilkinson, R. G., \& Pickett, K. E. (2009). Income inequality and social dysfunction. Annual Review of Sociology, 35, 493-511. doi:10.1146/annurev-soc-070308-115926

Wilkinson, R. G., \& Pickett, K. E. (2010). The spirit level. Why equality is better for everyone. London: Penguin.

Wilson, D. B. (2005). Meta-analysis macros for SAS, SPSS, and Stata. Retrieved from http://mason. gmu.edu/ dwilsonb/ma.html

van Zomeren, M., \& Klandermans, B. (Eds). (2011). Towards innovation in theory and research on collective action and social change [Special issue]. British Journal of Social Psychology, 50(4). doi:10.1111/j.2044-8309.2011.02078.x

Zinn, H. (1968). Disobedience and democracy: Nine fallacies on law and order. New York: Vintage.

Received 4 August 20I I; revised version received 22 June 2012

\section{Supporting Information}

The following supporting information may be found in the online edition of the article:

Appendix SI.A. Scales, main survey.

Appendix SI.B. Competence and warmth means for each cluster, within each sample.

Table SI.1. Demographic information, all samples, preliminary groups-listing study.

Table SI.2. Demographic information, all samples, main survey.

Please note: Wiley-Blackwell are not responsible for the content or functionality of any supporting materials supplied by the authors. Any queries (other than missing material) should be directed to the corresponding author for the article. 